\title{
Que eles falem por si: relatos dos profissionais sobre a experiência nas residências terapêuticas
}

\author{
Let them speak for themselves: reports from professionals \\ about their experiences in therapeutic residency training
}

Maria de Fátima de Araújo Silveira ${ }^{1}$

Hudson Pires de Oliveira Santos Junior ${ }^{2}$

${ }^{1}$ Departamento de Enfermagem, Universidade Estadual da Paraíba. Av. das Baraúnas 351, Campus Universitário Bodocongó. 58101-001 Campina Grande PB.

fatimasilveir@uol.com.br ${ }^{2}$ Departamento de

Enfermagem Materno-

Infantil e Psiquiatria, Escola de Enfermagem,

Universidade de São Paulo.

\begin{abstract}
This paper deals with qualitative research conducted in the Therapeutic Residency Service in the municipality of Campina Grande, State of Paraiba, Brazil, the objective being to ascertain the difficulties encountered by the professionals in the healthcare practices defined by the aforementioned service and identify the prospects identified by them for the residents. A semi-structured interview routine was conducted with ten professionals for the data collection, along with analysis of field records and systematic observation. The main difficulties faced are of a structural nature, namely lack of human resources and/or training and social support. Social reintegration, insertion in the workplace and autonomy are the expectations singled out by the professionals. In light of the results, it can be affirmed that, in spite of the difficulties experienced, it is possible to see progress, such as the autonomy of some residents. Nevertheless, as it is a recent service, it needs to be constantly evaluated.
\end{abstract}

Key words Mental health, Disinstitutionalization, Assisted living facilities
Resumo Trata-se de uma pesquisa qualitativa, realizada no Serviço de Residências Terapêuticas do município de Campina Grande, Paraíba, Brasil, cujo objetivo foi conhecer quais as dificuldades enfrentadas pelos profissionais na prática de cuidado delineada a partir do referido serviço e identificar quais são as perspectivas por eles apontadas para os(as) moradores(as). Para a coleta de dados, utilizou-se roteiro de entrevista semiestruturada aplicado a dez profissionais, registro em diário de campo e observação sistemática. Verificou-se que as principais dificuldades enfrentadas são de base estrutural, insuficiência de recursos humanos el ou falta de capacitação e de apoio social. A reinserção social, a inserção no mundo do trabalho e a autonomia são as expectativas apontadas pelos profissionais. Diante dos resultados, pode-se afirmar que, apesar das dificuldades vivenciadas, é possivel ver avanços, como a autonomia de alguns moradores. Todavia, por ser um serviço recente, precisa, constantemente, ser avaliado.

Palavras-chave Saúde mental, Desinstitucionalização, Moradias assistidas 


\section{Introdução}

Em um cenário de luta por reversão dos hospitais psiquiátricos para uma atenção inserida na comunidade, surgem, no Brasil, no início dos anos 1990, iniciativas pioneiras de estruturas residenciais extra-hospitalares, as quais tiveram a função de demonstrar, empiricamente, a viabilidade da substituição de leitos dos "moradores" dos asilos por casas no espaço comunitário, sendo a importância estratégica desse dispositivo ressaltada na II Conferência Nacional de Saúde Mental, em 1992.

Municípios como Porto Alegre (RS), Campinas (SP), Santos (SP) e Rio de Janeiro (RJ), por meio da implantação de seus "lares abrigados", "pensões protegidas", "moradias extra-hospitalares", como eram nomeadas as residências na década de 1990, foram precursores do serviço e geraram subsídios importantes para que a iniciativa viesse a ser incorporada como política do Sistema Único de Saúde (SUS) ${ }^{2}$.

Nos últimos anos, para se conseguir a efetiva desinstitucionalização e a reinserção dos portadores de transtornos mentais graves na comunidade, foram implantados os Serviços Terapêuticos Substitutivos, em especial as Residências Terapêuticas. Tal dispositivo de atenção foi instituído pela Portaria n ${ }^{\circ}$ 106/2000 do Ministério da Saúde ${ }^{3}$, passando a ser chamado de Serviço de Residência Terapêutica, cujos objetivos centrais são: promover a reinserção social de pessoas com longos períodos de internação psiquiátrica e proporcionar-lhes autonomia, através do processo de reabilitação psicossocial, com reaprendizagem de atividades cotidianas e sociais necessárias para vida em comunidade ${ }^{4}$.

Além da referida portaria, outros aparatos jurídico-políticos dão sustentação às Residênci-

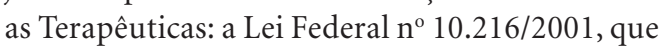
dispõe sobre a proteção e os direitos dos portadores de transtornos mentais; a Lei Federal $\mathrm{n}^{\circ}$ 10.708/2003, que institui o auxílio-reabilitação para usuários egressos de internações psiquiátricas; a Portaria do Gabinete do Ministro da Saúde (GM) nº 2.068/2004, que institui incentivo financeiro aos municípios para a implantação das residências; e as Portarias $n^{\circ} 52$ e $n^{\circ} 53 / 2004$, que estabelecem um programa de redução progressiva de leitos psiquiátricos no país ${ }^{3}$.

Diante disso, pode-se dizer que as Residências Terapêuticas são casas inseridas no espaço urbano, destinadas à moradia de pessoas egressas de longos anos de internações asilares e que perderam seus vínculos sociais e familiares. Tam- bém se prestam a servir de apoio a usuários de outros serviços de saúde mental que, por não contarem com o suporte familiar e social suficiente, não possuem garantia de espaço adequado de moradia.

Entretanto, é importante alertar que esses dispositivos não devem se configurar como mais um "serviço" de saúde, ainda que denominados "terapêuticos", pois tal denominação deve ser compreendida apenas como uma terminologia capaz de inserir um modelo diferencial de assistência à saúde mental no âmbito do Sistema Único de Saúde, respondendo à necessidade de moradia para sofredores psíquicos, bem como de realocar recursos de saúde para o município ${ }^{5}$.

Então, é primordial que as residências sejam vistas como espaços de morar/habitar, uma vez que já existem as ações assistenciais de saúde, implantadas pelo município, para uso e referência desses moradores, como é o caso do Centro de Apoio Psicossocial, assim como para o restante da população ${ }^{6}$. Ressalta-se, ainda, que a questão central das Residências Terapêuticas é o viver na cidade, é conquistar a cidadania, necessitando, para isso, de um espaço habitacional próprio, que se configure como um lar e não um local de tratamento 2 .

Contudo, não se pode negar, em seu todo, que o conjunto de pessoas que moram em uma dada Residência Terapêutica estão sendo cuidadas naquele espaço, pois são apoiadas no gerenciamento de suas vidas, quer seja por um profissional, quer seja por um amigo ou até mesmo por um vizinho ${ }^{7}$.

Devido a essas particularidades, a implantação das moradias vem sendo debatida em vários âmbitos, de maneira a garantir que esta alternativa seja a mais eficaz possível para auxiliar o morador em seu percurso, muitas vezes complexo, de reintegração à comunidade, buscando a progressiva inclusão social e sua emancipação pessoal - afinal, a finalidade principal é a moradia, o morar e o conviver na comunidade ${ }^{2}$.

Entretanto, cada moradia deve ser considerada única, sendo organizada segundo as necessidades, os gostos e hábitos de seus moradores, pois trata-se da construção de um modo singular de dispositivo, que visa dar conta da individualidade de cada caso ${ }^{2}$. E, dada a complexidade e a multiplicidade que envolvem as moradias, elas podem ser diferenciadas pelo grau de autonomia de seus moradores: residências de cuidado intensivo, de cuidado parcial e de alto grau de autonomia ${ }^{7}$. Casas com cuidado intensivo têm cuidadores 24 horas; as de cuidado semi-intensi- 
vo possuem cuidadores apenas durante o dia; já as casas de alto grau de autonomia não contam com nenhum ou quase nenhum tipo de cuidador. Geralmente, estas são casas que têm apenas empregada doméstica, e boa parte de seus custos é financiada pelos seus integrantes.

Todavia, apesar de tal distinção, é preciso ter sempre em mente que as residências têm seu tratamento centrado no modelo humanista, visando oferecer vivências enriquecedoras que promovam maior capacidade para os indivíduos enfrentarem os desafios da vida ${ }^{8}$.

No Brasil, a criação e o desenvolvimento de tal dispositivo de atenção à saúde mental vêm sendo amplamente discutidos, e, entre 2000 e 2007, a rede de Residências Terapêuticas quintuplicou. Em 2000, havia apenas quarenta Residências no país. Este número saltou para 475 em 2007, distribuídas em todo o território nacional ${ }^{9}$. Porém, tal valor ainda está aquém da necessidade do país, que se estima ser de $2.522^{6}$. Entretanto, ainda são raros os estudos publicados que relatam ou avaliam tanto o alcance e as possibilidades desse dispositivo de cuidado quanto os desafios enfrentados para sua manutenção.

Diante dessa realidade, urge a necessidade de se responder a alguns questionamentos sobre esses serviços substitutivos, particularmente aqueles que têm por objetivo oferecer um novo tipo de atenção para ex-internos(as) que não contam mais com apoio de familiares para voltar à comunidade ou cujas famílias não mais os(as) aceitam, como é o caso do Serviço de Residências Terapêuticas ou moradias e que constituem o problema da presente proposta: quais as dificuldades vivenciadas pelos profissionais na prática de cuidado a partir da Residência Terapêutica? Quais as perspectivas para os moradores na visão da equipe?

Para responder a tais questões, foram delimitados como objetivos conhecer as dificuldades enfrentadas pelos profissionais do Serviço de Residências Terapêuticas, como também identificar, na fala de tais profissionais, quais são as perspectivas que eles apontam para os(as) moradores(as).

\section{Percurso metodológico}

Em virtude do objeto escolhido para este estudo, optou-se pela metodologia de abordagem qualitativa, pois esta possui a capacidade de lidar com o significado atribuído pelos sujeitos aos fatos, relações, práticas e fenômenos sociais, ou seja, preocupa-se com a realidade que não pode ser quantificada, trabalhando com o universo dos significados, motivos, aspirações, valores e atitudes presentes nas relações e ações humanas ${ }^{10}$.

O estudo foi realizado em Campina Grande, que possui uma população estimada em 371.000 habitantes, localizando-se no interior do estado da Paraíba. A escolha por esse cenário se deu devido ao fato de este município estar experimentando e implementando medidas para a desinstitucionalização de pessoas com internações psiquiátricas de longa permanência. Tal processo se iniciou quando o Ministério da Saúde instituiu o Programa Nacional de Avaliação do Sistema Hospitalar/Psiquiatria 2003/2004 (PNASH/Psiquiatria). Um dos resultados da avaliação foi a desclassificação e o descredenciamento de oito hospitais no país, entre os quais estava um nesta cidade, e que respondia a grande parte da demanda de saúde mental da região geopolítica do Compartimento da Borborema (PB). A intervenção ocorreu com a desospitalização dos 176 internos da instituição, em abril de 2005, e terminou em julho do mesmo ano, com o descredenciamento do hospital da Rede SUS.

Campina Grande passou, então, a receber incentivos financeiros do Ministério da Saúde para a implantação de Centros de Apoio Psicossocial e Residências Terapêuticas. Firmou-se uma articulação entre a rede de saúde mental e o Serviço de Atenção Móvel às Urgências $\left(\right.$ Samu ${ }^{11}$. Em cerca de um ano, esse município conseguiu reverter seu modo de atenção à saúde mental, passando do modelo hospitalocêntrico para o modelo de atenção psicossocial.

No cenário atual, a cidade possui uma rede ampla de serviços substitutivos: um Caps II, um Caps III, dois CapSi (infantis), um CapSad (álcool e outras drogas), uma Unidade de Emergência Psiquiátrica, um Centro de Cultura e Lazer, nove miniequipes de saúde mental no Programa Saúde da Família, seis Residências Terapêuticas e o Programa de Volta para Casa, este com 41 usuários credenciados ${ }^{11}$.

Esses dispositivos de atenção à saúde mental são definidos como um espaço intermediário entre o hospital e a comunidade, devendo ter como princípios a relação, o diálogo, a inter-relação com os atores sociais da instituição, promoção, proteção e, principalmente, a reabilitação, desconstruindo/construindo o cenário dessa prática de saúde, criando uma nova cidadania e uma nova ética ${ }^{8}$.

Como atores da investigação do presente estudo, estão dez profissionais que atuam na equi- 
pe das seis Residências Terapêuticas do município: um coordenador, dois técnicos de referência e sete cuidadores. Os critérios de inclusão dos profissionais na amostra foram: integrar a equipe da Rede de Saúde Mental municipal, sendo contratados em decorrência do processo de desinstitucionalização; atuar, apoiando direta ou indiretamente os moradores das RT; participar do estudo por livre e espontânea vontade; e assinar o Termo de Consentimento Livre e Esclarecido. O não atendimento a qualquer dos critérios de inclusão estabelecidos foram considerados como critérios de exclusão no estudo.

Em fase prévia à coleta de dados, foi realizada uma reunião com os profissionais do Serviço de Residência Terapêutica, na qual foi apresentada a proposta de pesquisa, com seus objetivos, falou-se sobre o modo como seria executada, bem como houve a apresentação dos pesquisadores e o convite para participação do estudo. Após esse primeiro contato, buscamos os profissionais interessados em colaborar e, por meio do telefone, era marcado um local e data para realização da entrevista que, geralmente, ocorria nas próprias Residências Terapêuticas, porém em espaço reservado e privativo.

Isto posto, a identificação dos entrevistados nos discursos se faz da seguinte forma: P. (para profissional) e o $\mathrm{n}^{\circ}$, para identificação do participante, seguindo o critério de ordem de realização da entrevista. Não foi identificada a profissão dos entrevistados, para assegurar o seu anonimato, pois se trata de um grupo pequeno, o que pode acarretar a identificação dos atores e de seus discursos.

Os dados foram obtidos por meio da observação sistemática, a partir da qual eram registrados os contatos feitos com os entrevistados e o modo como estes se inseriam no processo de cuidar dentro das moradias. No roteiro para entrevista semiestruturada, abordando a visão dos profissionais sobre a experiência terapêutica na moradia, constavam as seguintes questões: como você vê a proposta de atenção à saúde mental dentro da Residência Terapêutica? Quais as dificuldades que você encontra nessa prática de cuidado? Na sua visão, quais são as perspectivas para os moradores?

Complementando o leque de ferramentas metodológicas, elaborou-se um diário de campo, no qual foram registradas as impressões do pesquisador, análises preliminares e outras informações que se fizeram necessárias, como a dinâmica do cotidiano das residências e as práticas de cuidado produzidas nelas.
No tratamento do conteúdo (corpus) das entrevistas, os discursos foram submetidos à análise de conteúdo ${ }^{12}$, do tipo temático, cujo produto originou categorias, ilustradas com depoimentos e recortes de falas dos(as) profissionais.

O desenvolvimento do estudo seguiu as normas da Declaração de Helsinque, de 1964, na versão de $2000^{13}$, e as diretrizes emanadas da Resolução no 196/96 do Conselho Nacional de Saú$\mathrm{de}^{14}$. Para operacionalização, o projeto foi submetido à apreciação do Comitê de Ética em Pesquisa da Universidade Estadual da Paraíba (CEP/ UEPB), só sendo executado após a anuência deste órgão.

\section{Resultados e discussão}

Como resultados, foram encontradas duas categorias analíticas, com seus respectivos núcleos de sentido (ou temas):

(1) Rompendo com o tradicional hermético e se abrindo ao cotidiano:

(a) Ausência de dificuldades no cuidado a sujeitos em sofrimento psíquico;

(b) Aspectos que transcendem a atuação e a vontade dos profissionais - falta de capacitação profissional, tempo insuficiente para cuidar, pouco suporte e estrutura das RT, falta de apoio e entrosamento da família.

(2) As moradias abrem perspectivas enriquecedoras:

(a) Reinserção social e familiar dos moradores;

(b) Inserção dos moradores no mundo do trabalho;

(c) Autonomia dos moradores.

Tais categorias e seus temas são apresentados e discutidos sequencialmente a seguir, à luz da observação sistemática e do referencial teórico encontrado.

\section{Rompendo com o tradicional hermético e se abrindo ao cotidiano}

No interior de um novo paradigma e de uma nova prática à saúde, que envolve, concomitantemente, a desospitalização e a implementação de iniciativas para reinserir o sofredor psíquico em seu meio social e familiar, buscamos identificar quais são as principais dificuldades encontradas pela equipe do Serviço de Residências Terapêuticas segundo a lógica antimanicomial.

Como respostas encontradas, a primeira é a "ausência de dificuldades no cuidado a sujeitos 
em sofrimento psíquico" (aqui, os moradores das RT), ou seja, há satisfação em trabalhar nesse dispositivo de cuidado - Residências Terapêuticas -, como expressam os discursos a seguir:

Pra mim, até agora, não tenho dificuldade nenhuma. (P., 5)

Bom, até agora, pra falar a verdade, eu não encontrei nenhuma dificuldade. Pra diferença do hospital João Ribeiro [hospital psiquiátrico], que a gente teve lá, aqui tá tudo perfeito. (P., 6)

A satisfação no trabalho é um estado emocional resultante da interação de profissionais, suas características pessoais, valores e expectativas com o ambiente e a organização do serviço ${ }^{15}$. De acordo com a análise e sua interface com a literatura, percebe-se que um dos fatores que contribuem para maior satisfação entre os profissionais é o fato de atuarem em um projeto assistencial "novo" e com status diferenciado, como é o Serviço de Residências Terapêuticas ${ }^{16}$.

Além disso, o processo de desinstitucionalização foi estruturado de modo que os internos só fossem transferidos quando houvesse condições de infraestrutura, equipe para a atenção direta, equipes matriciais para o acompanhamento e o referenciamento, e suporte aos profissionais dos serviços substitutivos, bem como a retarguarda garantida, através da implantação da Unidade de Urgência e Emergência.

Outra leitura refere-se ao fato apontado no segundo relato, de o profissional ter atuado, anteriormente, na instituição total - o hospital interditado e descredenciado - e perceber que a qualidade da atenção prestada leva à visibilidade de perspectivas, e, por que não, de avanços no processo de recuperação e ressocialização que os serviços substitutivos podem proporcionar, o que não ocorria no manicômio. A satisfação profissional decorre não apenas da remuneração, aqui entendida como salário direto, mas provém de outras fontes, e, no caso em tela, cuidar pressupõe um retorno do usuário, seja em melhoria da condição clínica, da ambiência qualificada para o acolhimento e conforto para os usuários, seja na retomada possível da vinculação com a família dos sujeitos, entre tantas possibilidades que se apresentam como horizonte para quem ali trabalha.

Ao mesmo tempo, por tratar-se de uma nova modalidade assistencial, ela traz o desconhecido, às vezes insuficientes referências teórico-práticas ou, ainda, dificuldade do profissional, tanto decorrente de uma lacuna acadêmica e de Educação Permanente em Saúde quanto de abertura para o novo e para a proposta que visa à construção de sujeitos, numa perspectiva de produ- ção de saúde e de vida, para grupos profissionais cujo mister era, até então, medicalizar a "população" do hospital psiquiátrico. Destaca-se, aqui, que a instituição descredenciada chegou a ter mais de quinhentos internos sob sua tutela. A partir de tais constatações, foi possível apreender e registrar, para análise, dobras presentes nos depoimentos que apontaram dificuldades presentes na dinâmica das moradias, "aspectos que transcendem a atuação e a vontade dos profissionais", entre estes a "falta de capacitação profissional".

A dificuldade que eu encontro nessa prática é a questão da capacitação, que é preciso ter mais capacitação continuada pra os profissionais que trabalham com saúde mental (P., 3).

No cotidiano da pesquisa, podemos observar que as capacitações ocorrem, apesar de serem esporádicas. Além disso, outro fato preocupante é o privilégio de cursos/treinamentos/capacitações para os profissionais de nível superior, alijando do processo os trabalhadores de nível escolar médio. Por se tratar de Residências Terapêuticas, são estes os sujeitos que estão no manejo, no contato e nos cuidados diários com os moradores.

Embora o Ministério da Saúde tenha criado Núcleos ou Polos Regionais de Capacitação e Produção de Conhecimento em diversas localidades do país, observa-se que alguns deles ainda estão em fase de implantação, e os que já estão instalados são recentes e têm organizado poucos cursos, mesmo assim de forma não sistematiza$\mathrm{da}^{17}$. Há também de se ressaltar que a maior parte de capacitações, eventos técnicos, estudos e pesquisas conveniadas com o Ministério da Saúde ainda está centralizada nos grandes centros urbanos e em número ainda insignificante ${ }^{15}$.

Outra dificuldade apontada é em relação ao "tempo insuficiente para cuidar", encontrada, particularmente, nos discursos dos cuidadores:

A dificuldade que eu acho nessas residências é que a gente não tem muito tempo pra se dizer cuidador. A função de cuidador é, realmente, cuidar deles, dar atenção a eles, e como a gente aqui toma conta da casa e deles, não sobra muito tempo pra eles; aí fica faltando muito espaço. Às vezes, eles querem brincar; às vezes, a gente quer ensinar. A gente não tem tempo de brincar com eles. Eles cobram muito isso da gente: atenção! Eles querem muita atenção e a gente não tem como dar. Eu acho que a gente deveria ter uma pessoa pra cuidar deles e outra pra cuidar da casa. (P., 7)

Esse dilema entre cuidar da casa e cuidar dos moradores é um ponto marcante nos discursos. Afinal, qual o papel do cuidador? Organizar a 
casa e dar atenção aos moradores? Se sim, como realizar ambos e com qualidade, principalmente quando o que está em foco é o cuidar do outro e de suas circunstâncias? Essas questões, na dinâmica da residência, mostram-se realmente conflituosas. Porém, não acreditamos que uma atribuição exclua a outra, pois é, mais do que possível, recomendável repensar a inserção dos cuidadores na RT.

Em decorrência do resultado desta pesquisa, apresentado e discutido com a equipe, a coordenação das moradias elaborou um plano de atuação para os cuidadores, com revezamento diário, de modo que dois profissionais permaneçam, por turno de sua jornada, simultaneamente, em cada residência, para que um deles possa responsabilizar-se pelo cuidado à casa e, particularmente, aos moradores que auxiliam nas tarefas domésticas, e o outro possa priorizar o cuidado aos outros moradores, através de passeios, conversas, jogos e outras atividades de recreação e lazer.

É importante pontuar que a interação do cuidador com o morador é fator de grande influência na recuperação e na reabilitação deste, pois permite que o profissional conheça as dificuldades concretas e materiais do que significa viver como sofredor psíquico ${ }^{18}$, necessitando ter, então, a oportunidade de exercer uma visão holística sobre o adoecimento mental, compreendendo-o sempre como um fenômeno complexo. Esse trabalho requer do profissional, além de tempo, competência e disponibilidade, a capacidade de abrir mão do poder que subjetivamente exerce sobre o morador, partindo do princípio de que a última palavra e a solução dos problemas estão em cada pessoa ${ }^{18}$.

Essa peculiaridade permite que cada componente da residência, usuário ou profissional, tenha o seu valor e a sua função, cada um contribuindo com o que pode, cada um ajudando a enfrentar seus medos, suas frustrações, facilitando, assim, a superação dos obstáculos diários da vida em sociedade ${ }^{11}$.

Outra dificuldade que apreendemos nos discursos diz respeito ao "pouco suporte e estrutura" das Residências Terapêuticas:

A única dificuldade que eu encontro é a dificuldade de trabalho. A gente não tem um carro disponivel pra trabalhar; a gente dispõe apenas de uma Kombi para transportar 45 usuários. Então, se eu tiver carro próprio, eu vou ter que trabalhar nele; se eu não tiver, eu vou ter que trabalhar a pé, de ônibus, de mototáxi. Então fica difícil, entendeu? (P., 3)
Observamos, como indica o discurso, carência de suporte e, principalmente, de estrutura física das moradias, porém não acreditamos que isso se pronuncie como um grave problema. Talvez o maior entrave esteja no olhar biomédico dos profissionais, que acreditam precisar de um carro a sua disposição por 24 horas, não atentando para o fato de que as moradias estão inseridas na comunidade, a qual possui um aparato de transportes públicos, além de outros equipamentos sociais, que poderiam e podem ser utilizados pelos moradores, cumprindo, assim, um dos pressupostos basilares da Reforma Psiquiátrica, qual seja o de criar e implementar dispositivos para que os sujeitos em sofrimento psíquico voltem a circular no meio social e comunitário, do qual não deveriam ter sido excluídos.

Todavia, essa carência de recursos guia nosso olhar para a necessidade de compreensão dos recursos financeiros do Serviço de Residências Terapêuticas municipal. Em um levantamento, constatou-se que as residências têm um gasto mensal de $\mathrm{R} \$ 40.500,00$, o equivalente a $\mathrm{R} \$ 900,00$ por morador ${ }^{11}$.

Tais valores explicitam que as Residências Terapêuticas não são equipamentos de custo baixo em relação ao custo hospitalar, pois, se a lógica da Reforma Psiquiátrica fosse apenas racionalizar recursos econômico-financeiros ${ }^{6}$, não seria vantajoso investir nesses dispositivos e na implantação de uma rede substitutiva. Pode-se afirmar que o processo de desinstitucionalização não passa por uma simples redução de recursos; ao contrário, o foco está em promover uma chance de resgate de vida aos sofredores psíquicos, de reconhecimento como sujeito, de cidadanização, de desobjetivação paralisadora que a instituição asilar imprime ${ }^{7}$. Poder retomar o convívio social em uma casa, em uma cidade, reaprender hábitos de que há muito se foi privado, pela lógica manicomial, requer dessas práticas um custo cujo resultado não tem valor monetário.

Para encerrar a sequência de dificuldades expressas pelos profissionais entrevistados, destacamos a "falta de apoio e entrosamento da família”. A ideia de que a família é o contexto social de grande relevância, no que diz respeito à saúde mental, encontra-se presente em variados estu$\operatorname{dos}^{19,20}$, e aqui se revela nas narrativas produzidas pelos entrevistados:

Uma grande dificuldade que eu vivencio no meu trabalho é a questão do entrosamento da família com esses usuários, que a gente sente muita dificuldade de inserir essa família no processo de reinserção social deles. (P., 2) 
Uma coisa que a gente, vez ou outra, a gente discute é como é difícil essa interação da família. Então, é muito pouco familiar que vai visitar eles. Então, eles sentem demais, a gente percebe isso, principalmente em épocas tipo o Natal. Então, é uma coisa, infelizmente, que a gente percebe que não existe ainda entrosamento. (P., 1)

A ausência dos familiares no cotidiano dos moradores da RT é o grande desafio a ser enfrentado, de modo geral, compreendendo-se que nem sempre essa organização social é profícua no cuidado com seus membros. Muitas famílias foram distanciadas dos seus parentes devido aos longos anos de internações psiquiátricas, aí incluídas algumas com quem a equipe e morador não têm mais contato; outras sequer desejam rever seus familiares, alegando não ter condição de cuidar e o medo de agressões. Ou seja, ainda há a visão cultural do "doente mental" como agente de periculosidade social.

Para fundamentar essa discussão, trazemos o conceito de família como uma unidade cujos membros podem ou não estar relacionados ou viver juntos ${ }^{21}$. Nela, existe um compromisso e um vínculo entre seus membros, e as funções de cuidado consistem em "proteção, alimentação e socialização".

Entretanto, essa estrutura familiar pode ser estremecida quando um dos seus componentes apresenta distúrbios mentais ou comportamentais, fato desencadeador de vários enfrentamentos para os familiares, e que, talvez, por não terem conhecimento suficiente sobre a doença vivenciada pelo seu parente, não conseguem compreender a evolução da sintomatologia dos distúrbios mentais, acabando por conduzir, na busca de uma via de "alívio", ao caminho dos hospitais psiquiátricos ${ }^{22}$. Entretanto, o acontecimento seguinte à internação psiquiátrica é a subtração de documentos, objetos pessoais, contato, dignidade, lembranças, laços sociais e familiares, restando, no fim, apenas o escuro e a solidão ${ }^{23}$.

Por isso, concordamos com a afirmação de que "os manicômios, além de serem miseráveis, são também vazios de relações afetivas"24. Por essa e por outras razões, o principal objetivo da Reforma Psiquiátrica é evitar que o sujeito adoecido mentalmente seja privado de seus laços afetivos e sociais.

Logo, para essa prática se efetivar, existe a premência de se ofertar suporte terapêutico para que os familiares possam cuidar, proteger e aliviar-se da sobrecarga vivida, possibilitando-lhes a construção de novos caminhos para lidar com seus sofredores psíquicos de forma mais livre e autônoma ${ }^{20}$.

\section{As moradias abrem perspectivas enriquecedoras}

Buscamos, na análise dos discursos, identificar quais são as perspectivas que os profissionais entrevistados conseguem visualizar para os usuários. Das citadas, uma se relaciona com o desejo de "reinserção social e familiar dos moradores", pois, apesar de esses sujeitos estarem fora dos muros hospitalares, há ainda outros muros a superar, que são os construídos pelo vazio e pela falta de laços sociais ${ }^{22}$.

A gente espera que eles voltem a conviver no seu lar, com a sua família, que, pra eles, vai ser bem melhor voltar a viver dentro do seu próprio lar, sendo essa a expectativa da saúde mental. (P., 4)

O desejo relatado é a reinserção, tanto na esfera social quanto na familiar. Porém, isso não configura uma meta de rápido ou fácil alcance. Mas a caminhada já foi iniciada, com a retirada desses sujeitos do hospital psiquiátrico. Agora, acreditamos que é necessário lançar mão dos aparatos técnico-assistencial e sociocultural, na busca de introduzir uma nova concepção social em relação ao sofrimento psíquico, demonstrando, através dos meios pertinentes, a possibilidade de uma convivência mútua e de gerenciamento de conflitos, de modo a não esgarçar ainda mais o tecido social para onde retornam os egressos das instituições totais.

A construção de um outro lugar para a "loucura" que não seja o da doença, da anormalidade, da periculosidade, da incompetência e do erro implica, entre outras coisas, uma detalhada revisão do conjunto de representações que atravessam a sociedade e que acompanham os indivíduos tomados como loucos. Por isso, as novas tecnologias - serviços substitutivos - atreladas às recentes políticas públicas na área da saúde mental não podem ser pensadas e abordadas sem que se levem em consideração as atuais práticas e os imaginários sociais que envolvem a doença mental ${ }^{23}$.

Complementando esse raciocínio, pode-se afirmar que a implantação de ações que venham a garantir ao sofredor psíquico uma assistência digna pressupõe o enfrentamento de muitos conceitos sobre loucura e sofrimento psíquico, para que o indivíduo adoecido mentalmente seja visto como um sujeito de direitos que necessita de cuidados, sem necessariamente perder sua liberdade e autonomia ${ }^{25}$, pois a desinstitucionalização significa tratar o sofredor psíquico em sua existência e em relação com suas condições concretas de vida; não administrar-lhe apenas fárma- 
cos ou psicoterapias, mas construir possibilida$\operatorname{des}^{26}$. Logo, o tratamento deixa de ser a exclusão em espaços de violência e mortificação para tornar-se criação de possibilidades concretas de sociabilidade e subjetividade.

A segunda perspectiva apontada pela equipe do Serviço de Residências Terapêuticas é o anseio de "inserção dos moradores no mundo do trabalho":

Esperamos que eles [moradores] tenham condições de até chegar a ter um emprego, se alguma empresa desse essa chance, oportunidade, pra eles ficarem em uma atividade que não tivesse perigo, alguma coisa, quem sabe cumprir um horário como uma jornada de trabalho. (P., 9)

No período de observação, notamos que alguns moradores apresentam capacidade de desenvolver atividades laborais. Todavia, essa questão de profissionalização e geração de renda são pontos que ainda estão a se desenhar a passos lentos nos Caps, pois se trata de uma demanda intersetorial, para a qual ainda não existem ações bem consolidadas no país, particularmente no âmbito da atenção à saúde mental.

Existem três aspectos importantes quanto ao significado cultural do trabalho na atribuição de normalidade ${ }^{27}$. Em primeiro lugar, a disposição para o trabalho está relacionada à força - entendendo-a como estado de plena posse de capacidades físicas e mentais. A concepção do que é ser trabalhador se relaciona, também, ao cumprimento de expectativas sociais. Mais do que isso, o exercício do trabalho é tido como participante e mantenedor de redes de reciprocidade no interior da família, o que geralmente se quebra quando do surgimento da doença mental.

Porém, para os sofredores psíquicos, o trabalho não tem apenas a função de inserção no mundo da coletividade, de rompimento do isolamento que caracteriza a vivência social dos adoecidos mentalmente. O trabalho possui a capacidade de tornar os sujeitos agentes ativos no mundo em que vivem e não apenas espectadores passivos ou submissos do que acontece ao seu redor ${ }^{16}$.

Essa "autonomia para os moradores" surge como terceira, mas não menos importante, perspectiva dos profissionais, sendo bem representada pelo discurso a seguir:

O principal é tentar fazer com que eles possam, eles morem sozinhos, eles mesmo cuidem da casa, façam a alimentação deles. O técnico vai ficar só observando, mas eu acho que tem que ser um período muito grande. Já tem residência que eles moram só, vão ao supermercado e a proposta de todas as residências é a mesma. (P., 8)
Esse novo modo de viver tem possibilitado aos moradores um ganho de autonomia que faz diferença em suas vidas. Há moradores que já circulam pelo território de maneira mais autônoma, com inserção na escola, em grupos religiosos:

Tem um morador que ele já estuda, ele frequenta a igreja evangélica, ele frequenta a terapia do amor, já fez cartão do $Y$ [supermercado], cartão da $Z$ [loja de vestuário]. Ele é bem desenrolado mesmo, ele participa mesmo da sociedade, vai pro centro com suas coisas. É assim! (P., 10)

Limpar um jardim, comprar mercadorias, descobrir as maneiras de interagir com as pessoas, desenvolver um trabalho, fazer amizades, descobrir os direitos, encontrar um namoro, ir à igreja, acompanhar o movimento da cidade, são estratégias dotadas de fundamental capital afetivo e simbólico que ajudará o sofredor psíquico no resgate da sua cidadania ${ }^{20}$.

É importante fecundar a concepção de cidadania, na qual ser cidadão não implica apenas reconhecimento de direitos, mas, sim, um processo ativo de ampliação da capacidade de autonomia e liberdade, de modo que a "loucura" não signifique limitações e incapacidades.

A autonomia leva a viver o cotidiano da cidade, permitindo àquele que, muitas vezes, fica à margem da história tornar-se autor da própria vida, exceder o papel de doente e deslocar-se em direção a outros papéis: o de cidadão, de portador de direitos, de consumidor, de produtor ${ }^{11,20}$.

Logo, percebemos que, nas residências, o cuidado não é apenas realizado nos serviços substitutivos que o morador frequenta, como no Centro de Apoio Psicossocial, no Centro de Convivência, entre outros, mas há uma lógica de cuidado que é produzido na casa, ou a partir da casa, quer seja na rua, quer seja no supermercado, no cinema, no banco, na escola, enfim, nos inúmeros lugares de circulação do sujeito pelo território.

\section{Considerações finais}

Antes de pensar na Reforma Psiquiátrica e tentar compreendê-la, faz-se necessário ter em mente que tal processo vem acompanhado de uma mudança de paradigma, em que o foco passa do modelo flexneriano para o holístico, isto é, sai da visão fragmentada sobre o sujeito e passa a entendê-lo como integrante de um contexto biossocioeconômico-cultural.

E foi com esse outro olhar sobre o processo saúde-doença que partimos para executar este 
estudo, e foi com ele que chegamos às considerações finais acerca dos resultados encontrados.

Diante disso, podemos afirmar que a prática de atenção à saúde mental a partir das Residências Terapêuticas conduz os profissionais a "novas" práticas em saúde e abre perspectivas enriquecedoras, envolvendo o resgate de diálogo entre o conhecimento e a realidade de mundo, rompendo com o tradicional hermético e se abrindo ao cotidiano, necessários para a manutenção da saúde mental.

Outro ponto também constatado é o fato de que as dificuldades enfrentadas pelos profissionais se caracterizam por ser de base estrutural, de recursos humanos e de apoio social, podendo vir a se configurar como entrave para o alcance das perspectivas, as quais são: reinserção social, familiar e no mundo do trabalho e desenvolvimento da autonomia.

Portanto, não podemos afirmar que as residências já se configuram na forma ideal de prestar assistência aos sofredores psíquicos, mas, sim, podemos registrar que o caminho é esse, o da desinstitucionalização, caracterizando-se como o caminho de retorno para a sociedade e para as relações sociais.

Todavia, tais dispositivos de atenção precisam ser constantemente avaliados, para que não se corra o risco de se perder em suas características e para que a Reforma Psiquiátrica atinja, devidamente, seus fins e não padeça como mera fachada de uma política insubsistente.

\section{Colaboradores}

MFA Silveira e HPO Santos Junior participaram igualmente de todas as etapas da elaboração do artigo. 


\section{Referências}

1. Brasil. Ministério da Saúde. Relatório Final da II Conferência Nacional de Saúde Mental. Brasília: Centro de Documentação da Saúde do Brasil; 1994.

2. Brasil. Ministério da Saúde. Secretaria da Atenção à Saúde. Residências terapêuticas: o que são, para que servem. Brasília: Ministério da Saúde; 2004.

3. Brasil. Ministério da Saúde. Secretaria de Atenção à Saúde. Legislação em Saúde Mental: 1990-2004. $5^{a}$ ed. Brasília: Ministério da Saúde; 2004.

4. Weyler AR, Fernandes MIA. Os caminhos das propostas de moradias para ex-pacientes psiquiátricos. Vínculo 2005; 2(2):80-88.

5. Brasil. Ministério da Saúde. Documento apresentado na Conferência Regional de Reforma dos Serviços de Saúde Mental: 15 anos depois de Caracas. Brasília: Ministério da Saúde; 2005.

6. Furtado JP. Avaliação da situação atual dos Serviços de Residências Terapêuticas no SUS. Cien Saude Colet [periódico na Internet]. 2006 [acessado 2007 jan 27]; 11(3):785-795. Disponível em: http: www. scielo.br/pdf/csc/v11n3/30993.pdf

7. Freire FHMA. Residência terapêutica: inventando novos lugares para se viver [dissertação]. Rio de Janeiro: Universidade Federal do Rio de Janeiro; 2006.

8. Oliveira FB, Fortunato ML. Saúde mental: reconstruindo saberes em enfermagem. Rev Bras Enferm 2003; 56(1):67-70.

9. Brasil. Ministério da Saúde. Secretaria de Atenção à Saúde/DAPE. Saúde mental no SUS: acesso ao tratamento e mudança no modelo de atenção. Relatório de Gestão 2003-2006. Brasília: Ministério da Saúde; 2007.

10. Minayo MCS. O desafio do conhecimento: pesquisa qualitativa em saúde. 6a ed. São Paulo: Hucitec; 1999.

11. Santos Junior HPO, Gualda DMR, Silveira MFA. Similarities and differences arising from accommodation and care issues in half-way houses: qualitative approach. Online Brazilian Journal of Nursing [serial on the Internet]. 2008 [cited 2009 June 28]; 7(3):[cerca de 12p.]. Available from: http:// www.uff.br/objnursing/index.php/nursing/article/ view/j.1676-4285.2008.1871/432

12. Bardin L. Análise de conteúdo. $3^{\mathrm{a}}$ ed. Lisboa: Edições 70; 2006.

13. Brasil. Ministério da Saúde. Conselho Nacional de Saúde. Comissão Nacional de Ética em Pesquisa Conep. Resolução no 196/96. Dispõe sobre pesquisa envolvendo seres humanos. Brasília: Ministério da Saúde; 1996.

14. World Medical Association. 52 $2^{\text {nd }}$ General Assembly of the World Medical Association. Declaration of Helsinki: recommendation guiding physicians in biomedical research involving humans subjects, 1964. Edimburgo: World Medical Association; 2000.
15. Rebouças D, Legay LF, Abelha L. Satisfação com o trabalho e impacto causado nos profissionais de serviço de saúde mental. Rev Bras Enferm 2007; 2(41):31-33.

16. Vicente B, Vielma M, Jenner FA, Mezzina R, Lliapas I. Attitudes of professional mental health workers to psychiatry. Int J Soc Psychiatry 1993; 39(2):131-141.

17. Brasil. Tribunal de Contas da União. Secretaria de Fiscalização e Avaliação de Programas de Governo. Relatório de Avaliação de Programa: ações de atenção à saúde mental. Brasília: TCU; 2005.

18. Campos RO. Clínica: a palavra negada - sobre as práticas clínicas nos serviços substitutivos de saúde mental. Saúde em Debate 2001; 25(58):98-111.

19. Organização Mundial da Saúde (OMS). Organização Pan-Americana da Saúde (Opas). Relatório sobre a saúde no mundo. Saúde Mental: nova concepção, nova esperança. Genebra: OMS; 2001.

20. Dalmolin BM. Esperança equilibrista: cartografias de sujeitos em sofrimento psíquico. Rio de Janeiro: Editora Fiocruz; 2006.

21. Bousso SR, Ângelo M. Fundamentos da assistência à família em saúde. Manual de Enfermagem - Programa de Saúde da Família. São Paulo: Ministério da Saúde; 2001.

22. Parente ACM, Pereira MAO. Percepção de pacientes psiquiátricos sobre suas famílias: um espelho de dois lados. Rev Bras Enferm 2004; 1(47):44-47.

23. Weyler AR. O hospício e a cidade: novas possibilidades de circulação do louco. Imaginário 2006; 12(13):381-385.

24. Saraceno B. Libertando identidades. Rio de Janeiro: Instituto Franco Basaglia, Te Coroá; 1999.

25. Dias M. Saúde mental: é possível uma política de saúde pública, coletiva, integrada e de cidadania. Divulgação em Saúde para Debate 2001; 23:86-95.

26. Amarante P. Novos sujeitos, novos direitos: o debate em torno da Reforma Psiquiátrica. Cad Saude Publica 1995; 11(3):491-494.

27. Rabelo MCM, Alves PCB, Souza IM. Signos, significados e práticas relativas à doença mental. In: Rabelo MCM, Alves PCB, Souza IM, organizadores. Experiência de saúde e narrativa. Rio de Janeiro: Editora Fiocruz; 1999. p. 45-73.

Artigo apresentado em 26/05/2008

Aprovado em 16/06/2009

Versão final apresentada em 18/07/2009 